\title{
Análise da variabilidade de isoenzimas em acessos e cultivares de girassol(1)
}

\author{
Rogério Fernandes de Souza ${ }^{(2)}$ e Eucleia Primo Betioli Contel(3)
}

\begin{abstract}
Resumo - O número de genótipos de girassol (Helianthus annuus L.) disponíveis aos agricultores é pequeno e pouco se conhece sobre os genótipos provenientes de outros países que possam ser utilizados no melhoramento genético desta cultura. O objetivo deste trabalho foi analisar a variabilidade genética de 31 acessos e de cinco cultivares nos sistemas isoenzimáticos fosfoglicomutase (PGM), 6-fosfogliconato desidrogenase (PGD), fosfoglicoisomerase (PGI) e esterase (EST). Utilizou-se a técnica de eletroforese em gel de amido/penetrose para o fracionamento das isoenzimas da PGM, PGI e PGD e focalização isoelétrica para EST. Foram detectados um total de seis locos e 14 alelos para estes quatro sistemas. Observou-se variantes alélicas para os locos Pgi2, Pgm1, Pgd2, cada um com dois alelos, e para Est1, que apresentou seis alelos. Os testes de adequação aos modelos de equilíbrio de Hardy-Weinberg e de Wright evidenciaram que em dez acessos houve um desvio significativo de endocruzamento.
\end{abstract}

Termos para indexação: Helianthus annuus, proteínas, polimorfismo enzimático, variação genética.

Isozyme variability analysis in plant introductions and cultivars of sunflower

\begin{abstract}
The amount of available genotypes of sunflower (Helianthus annuus L.) to the agriculturists is minimum and the knowledge concerning genotypes from other countries, which could be used in this crop plant breeding is scarcely known. This work had the purpose of assessing the genetic variability of 31 accessions and of five cultivars to the isoenzymatic systems phosphoglucomutase (PGM), phosphogluconate dehydrogenase (PDG), glucose-6-phosphate isomerase (PGI) and carboxylesterase (EST). The starch or penetrose gel electrophoresis technique was applied aiming the fractionation of the PGM, PGI and PGD isoenzymes, and the EST isoelectric focusing. Six loci and 14 alleles to these four systems were detected. Allelic variation were observed on the Pgi2, Pgm1, Pgd 2 loci, two alleles each, and to Est1, which displayed six alleles. The goodness of fit tests for the Hardy-Weinberg and Wright equilibrium models indicated that ten accession showed a significant excess of selfing.
\end{abstract}

Index terms: Helianthus annuиs, proteins, enzyme polymorphism, genetic variation.

\section{Introdução}

O girassol (Helianthus annuus L.) é uma planta anual da família Asteraceae que tem como centro de origem a América do Norte. Atualmente, a produção mundial desta cultura oscila ao redor de 22 milhões

(1) Aceito para publicação em 27 de julho de 2000. Extraído da tese de doutorado apresentada pelo primeiro autor à Universidade de São Paulo (USP). Parcialmente financiado pela CAPES.

(2) Universidade Estadual de Londrina, Dep. de Biologia Geral, Caixa Postal 6001, CEP 86051-970 Londrina, PR E-mail: rogfs@uel.br

(3)USP, Faculdade de Medicina de Ribeirão Preto, Dep. de Genética, Av. Bandeirantes, 3900, CEP 14049-900 Ribeirão Preto, SP. E-mail: epbcontel@rgm.fmrp.usp.br de t/ano, o que a faz ocupar o quarto lugar como fonte mundial de óleo comestível, perdendo em importância apenas para a soja, o dendê e a canola.

Os seus maiores produtores são a Argentina, Rússia, França, Ucrânia e Estados Unidos (CarrãoPanizzi \& Mandarino, 1994; Estados Unidos, 2000).

No Brasil, a área de plantio tem aumentado significativamente nos últimos anos, sendo que a produção passou de 20,4 mil t na safra de 1997 para 102 mil t na de 1998 (Buzzetti, 1999).

A grande vantagem econômica desta cultura está justamente na capacidade de fornecer altas proporções de óleo, que é de fácil extração e de ótima qualidade (Embrapa, 1980; Reyes et al., 1985; Mandarino, 1992). Além disso, os subprodutos do girassol, tais como o farelo, a farinha ou o concen- 
trado protéico, podem ser utilizados na produção de silagem e rações de animais domésticos, na indústria de biscoitos e de outros produtos de panificação e em alimentos infantis e dietéticos.

Como no Brasil a produção é relativamente recente, o número de genótipos disponíveis aos agricultores é pequeno, sendo a maioria proveniente de empresas privadas que os desenvolvem em outros países com características de solo e clima diferentes (Reyes et al., 1985; Castiglioni \& Balla, 1996). Com o aumento do interesse por esta cultura, cresce a necessidade de desenvolvimento de materiais adaptados que tenham boas características agronômicas, tais como produtividade, resistência a doenças prevalecentes nas regiões de plantio e precocidade. Para tanto, a formação de um banco de germoplasma representativo e bem caracterizado torna-se essencial para se alcançar esses objetivos.

Segundo Kahler \& Lay (1985), técnicas bioquímicas e moleculares, tais como eletroforese de isoenzimas, oferecem marcadores genéticos que podem ser utilizados para caracterizar germoplasma. A identificação de genótipos de girassol tem se baseado em análises de caracteres morfológicos (Carrera \& Poverene, 1991). É sabido que estes caracteres, normalmente poligênicos, sofrem grande influência ambiental e se expressam em estádios distintos do desenvolvimento da planta. Isto aumenta o tempo e o custo necessários para a identificação ou a caracterização destes materiais. Por outro lado, isoenzimas são produtos primários dos genes, e variações na sua estrutura facilmente detectáveis e menos suscetíveis a influências ambientais podem oferecer informações úteis acerca da variabilidade no genoma (Shamina et al., 1998). Além disso, a sua análise pode ser feita, de modo geral, diretamente nos aquênios, ou então em plântulas. A extração de isoenzimas dos aquênios evita a necessidade de plantio em casa de vegetação, e quando o plantio é necessário, não compromete a viabilidade da semente, uma vez que apenas um dos cotilédones pode ser utilizado (Carrera \& Poverene, 1991; Quillet et al., 1992).

Marcadores isoenzimáticos têm sido utilizados com sucesso na identificação e caracterização da variabilidade genética de cultivares, populações naturais e acessos de bancos de germoplasma em dife- rentes culturas, tais como caqui (Tao \& Sugiura, 1987), kiwi (Messina et al., 1991), batata-doce (Kennedy \& Thompson, 1991), framboesa (Cousineau \& Donnelly, 1992), cevada (Hintum et al., 1995), girassol (Quillet et al., 1992; Voest et al., 1993; Carrera \& Poverene,1995; Cronn et al., 1997), mamão-papaia (Huang \& Layne, 1997), mandioca (Epperson et al., 1997), gramínea de pastagem Lolium perenne (Ursla-Fernando et al., 1997), feijão-lima (Maquet et al., 1997; Bi et al., 1998), aveia (Matiello et al., 1998) e feijão-fava (Polignano et al., 1998).

O objetivo deste trabalho foi caracterizar a variabilidade isoenzimática de acessos e cultivares de girassol através de diferentes marcadores enzimáticos, procurando determinar o grau de diversidade genética destes materiais.

\section{Material e Métodos}

Os aquênios de 31 acessos e de cinco cultivares de girassol utilizados neste estudo foram obtidos junto ao banco de germoplasma da Embrapa-Centro Nacional de Pesquisa de Soja, Londrina, Paraná. Cada acesso, representado por 100 aquênios, foi semeado a mão para se evitar mistura e contaminação. Na multiplicação, que ocorreu no campo, na safra de verão de 1997 , foram cruzadas manualmente todas as plantas entre si. Dez dias antes do florescimento, os capítulos foram protegidos com um saco de pano para evitar a contaminação por grãos de pólen de outros materiais. A trilhagem também foi realizada a mão, para evitar mistura e contaminação das amostras.

A extração das proteínas foi feita em água, e cada aquênio foi triturado individualmente com o auxílio de um pistilo de porcelana em uma placa de granito mantida em baixa temperatura. Foram utilizados trinta aquênios de cada acesso ou cultivar, na determinação do perfil eletroforético dos sistemas isoenzimáticos fosfoglicoisomerase (PGI, EC 5.3.1.9), 6-fosfogliconato desidrogenase (PGD, EC 1.1.1.44), fosfoglicomutase (PGM, EC 5.4.2.2) e esterase (EST, EC 3.1.1.1). A eletroforese foi realizada em gel de amido (Sigma) a $11 \%$ ou penetrose (amido de milho obtido na Refinações de Milho Brasil Ltda) a 13\%, com os seguintes tampões: ácido bórico 0,3 M, pH 8,6 (eletrodos) e TRIS 0.076 M ácido cítrico 0,005 M, pH 8,7 (gel), nos sistemas PGI e PGD; e ácido bórico 0,3 M, pH 8,6 (eletrodos) e TRIS 0,009 M - ácido cítrico 0,001 M, pH 8,5 (gel) no sistema PGM. Em EST, utilizou-se a técnica de focalização isoelétrica em gel de poliacrilamida com o anfólito Pharmalyte $\mathrm{pH}$ 4,2-4,9 com os tampões ácido glutâmico 
0,1 MeNaOH 0,1 N.A revelação dos sistemas enzimáticos foi baseada em Alfenas et al. (1991), e a nomenclatura dos locos isoenzimáticos seguiu o método adotado por Rieseberg \& Seiler (1990), no qual a numeração dos locos e de seus respectivos alelos iniciou-se a partir da região mais anódica. As estimativas das freqüências alélicas, bem como os parâmetros heterozigosidade observada $\left(\mathrm{H}_{\mathrm{o}}\right)$, heterozigosidade esperada $\left(\mathrm{H}_{\mathrm{e}}\right)$, proporção de locos polimórficos (P), distância genética (Nei, 1972) e o ajuste ao modelo de equilíbrio de Hardy-Weinberg foram feitos de acordo com o programa TFPGA (Miller, 2000). O ajuste ao modelo de equilíbrio de endocruzamento de Wright foi desenvolvido em planilha eletrônica. O seu teste de adequação foi realizado por meio de uma análise conjunta de $\chi^{2}$ com todos os locos dos acessos que não se encontravam em equilíbrio de Hardy-Weinberg e que apresentaram uma estimativa positiva do índice médio de fixação $(\bar{f})$. Os parâmetros número de alelos por loco $(\mathrm{Pa})$ e número médio de alelos por loco polimórfico (Ap) foram obtidos de acordo com Alfenas et al. (1991), e o índice médio de fixação $(\bar{f})$, e o modelo de equilíbrio de Wright, de acordo com Hartl (1981).

\section{Resultados e Discussão}

O zimograma da PGI mostrou duas regiões de bandamento (Figura 1), sendo que a mais anódica (Pgil) corou-se pouco e apresentou uma variação muito sutil na sua migração, o que não permitiu a discriminação dos indivíduos estudados. Isto não aconteceu com a segunda região (Pgi2), que mostrou bandas muito bem coradas e com mobilidades bastante distintas. Resultados semelhantes, para o padrão de bandamento dos produtos destes dois locos, foram observados por Carrera \& Poverene (1991, 1995). A enzima PGD teve duas regiões de migração, e foi a mais anódica (Pgdl), de difícil caracterização, tendo em vista a inconsistência na coloração, posição e tamanho das bandas. O número de locos e o padrão de bandamento observados nesta enzima se assemelham aos obtidos por Carrera \& Poverene (1991) e Quillet et al. (1992). Na PGM, detectaramse duas bandas distintas, sendo, a menos anódica, invariável $(P g m 1)$ em todas as amostras analisadas. Em seus estudos com a PGM, Kahler \& Lay (1985) e Carrera \& Poverene (1991) observaram quatro zonas de coloração, com variação apenas no loco mais anódico. Apesar das diferenças na quantidade de locos encontrados, o padrão de segregação da Pgm 1 nos presentes experimentos foi semelhante ao obtido por estes autores. Com relação a EST, a análise realizada através da eletroforese em gel de amido apresentou resultados semelhantes aos encontrados por Dry (1985) e Carrera \& Poverene (1991). Observou-se, neste sistema, apenas uma região de coloração bastante variável e de difícil caracterização. Quillet et al. (1992) encontraram duas formas de EST, sendo a mais anódica de coloração bastante fraca. Utilizando a técnica de focalização isoelétrica, foi possível detectar uma única região para EST. Entretanto, houve uma separação eficiente das variantes isoenzimáticas neste loco (Est1), que apresentou um número grande de alelos.

As freqüências alélicas dos locos polimórficos são mostradas na Tabela 1. Nos locos Pgi2, Pgd2 e Pgm 1 observaram-se apenas dois alelos (Figura 1). Já em Est1 detectaram-se seis alelos distintos. Quanto no $P g i 2$, notou-se maior freqüência do alelo $a$ em todos os acessos; este foi o único encontrado nas cultivares analisadas. No loco Pgd2, somente as PI's 219649, 372176 e 497930 tiveram fixado o alelo $b$. Todos os outros genótipos, inclusive as cultivares, apresentaram os dois alelos. Já no Pgm1, em 10 dos 31 acessos só se observou o alelo $b$, e em um, o alelo $a$. Este último parece também estar fixado nas cultivares M734 e M742. No Est1, a PI 500686 e a Cargill 11 foram os únicos genótipos que apresentaram apenas um dos seis alelos encontrados. Todos os outros genótipos mostraram pelo menos dois alelos nesse loco, sendo $a, d$ e $f$ os mais freqüentes. Por outro lado, o alelo Est l-e foi observado apenas na cultivar PI 432514.

As amostras das cultivares Cargill 11 e M734 não apresentaram variação em nenhum dos locos analisados, demonstrando, assim, maior homogeneidade nas linhagens que lhes dão origem. Já M742 apresentou variação apenas no loco $P g d 3$, o que pode significar que pelo menos um dos progenitores ainda segrega para este loco. DK 180 mostrou variação nos locos Pgd3, Pgml e Est1. Resultado semelhante ocorreu com a cultivar Embrapa 122.

De modo geral, os alelos mais freqüentes nos acessos foram os encontrados em maior proporção nas cultivares. Isto fica bastante evidente no alelo Pgi2-a, tendo ele se fixado em $35 \%$ dos acessos e em todas 


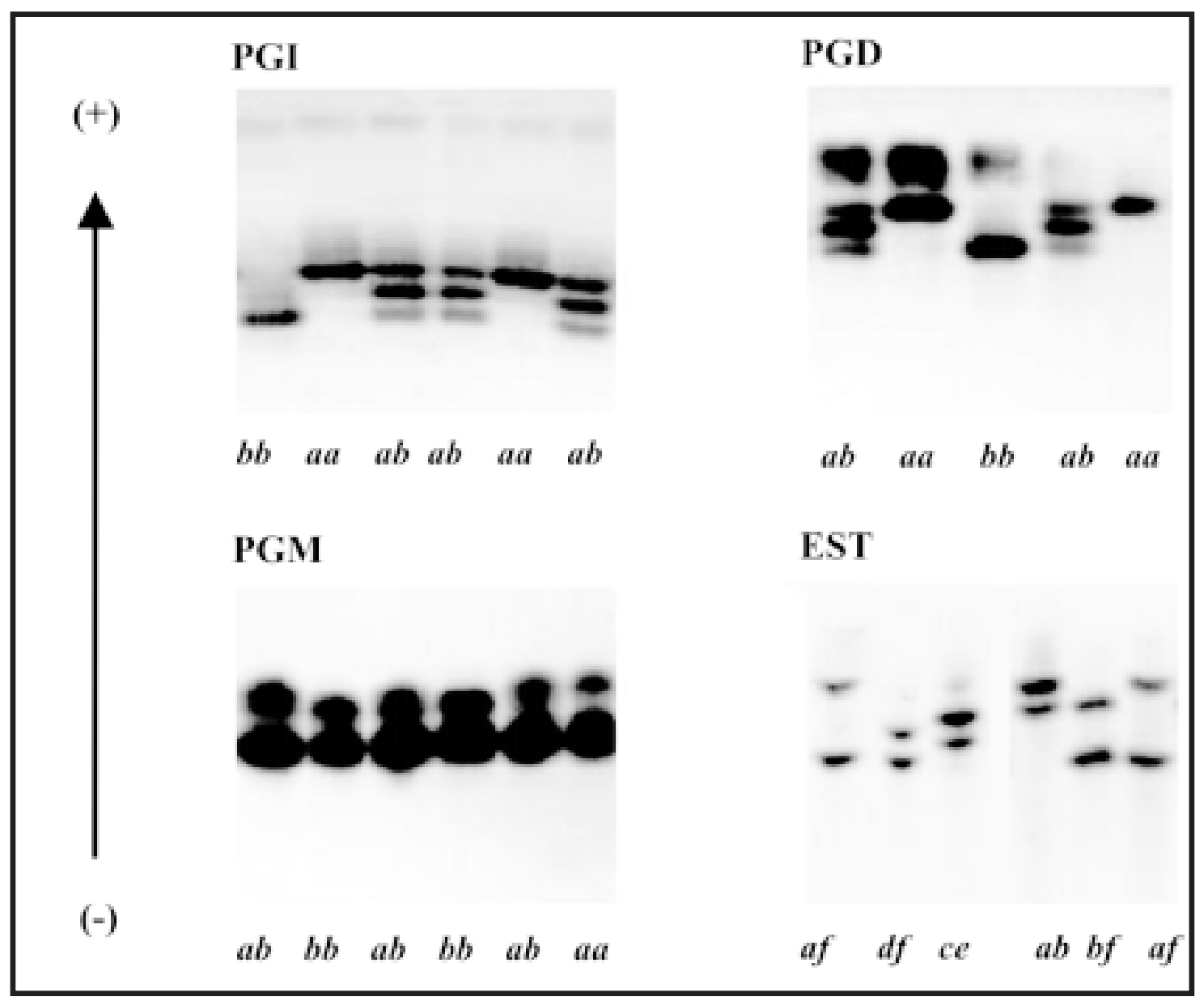

Figura 1. Zimogramas das enzimas fosfoglicose isomerase (PGI), 6-fosfogliconato desidrogenase (PGD), fosfoglicomutase (PGM) e esterase (EST) de girassol. Os fenótipos de cada indivíduo estão indicados.

as cultivares estudadas. $\mathrm{O}$ mesmo aconteceu com os alelos $a, d$ e $f$ do loco Est1. Isto, entretanto, não ocorreu para o loco Pgm1, onde o alelo a, em menor freqüência nos acessos, foi o menos freqüente apenas na cultivar EMBRAPA 122

O número médio de alelos por loco polimórfico (Ap) e o número médio de alelos por loco $(\mathrm{Pa})$ nas cultivares foi de 1,8 e 0,58 , respectivamente. Já a proporção média de locos polimórficos $(\mathrm{P})$ nestes mesmos genótipos foi de $40 \%$. Estes valores são menores que os observados nos acessos (Tabela 2). Isto, de certa forma seria esperado, tendo em vista que, durante o processo de melhoramento genético para obtenção de cultivares, parte da variabilidade é perdida. Por outro lado, o número maior de acessos analisados em relação ao número de cultivares pode aumentar esta diferença, devido ao viés tamanho amostral. Cronn et al. (1997), estudando acessos selvagens e domesticados, bem como cultivares de girassol, observaram que, em acessos domesticados, as estimativas de Ap, Pa e P foram de 2,05, 1,39 e 0,37 , respectivamente. Já nas cultivares, esses valores foram de $2,06,1,41$ e 0,39 , respectivamente. Em comparação com os dados deste experimento, pode-se observar que as maiores discrepâncias estão relacionadas às estimativas de $\mathrm{Pa}$ tanto nos acessos, como nas cultivares. Os valores obtidos por estes pesquisadores são cerca de duas vezes maiores que 
os observados nos acessos e cerca de três vezes maiores nas cultivares. Entretanto, estas diferenças podem ser explicadas pelo número menor de sistemas enzimáticos e de genótipos utilizados neste experimento.

Os modelos de equilíbrio de Hardy-Weinberg e de Wright foram aplicados somente aos acessos, tendo em vista que as cultivares são produzidas a partir de cruzamentos dirigidos, o que introduz um viés na estimativa destes parâmetros, bem como nas estimativas de heterozigosidade (Tabela 2). Embora representem materiais melhorados, os acessos foram multiplicados de forma a garantir o máximo possível da panmixia, para preservar a variabilidade genética neles presente. Dos 31 acessos analisados, 17 parecem estar em equilíbrio de Hardy-Weinberg e dez em equilíbrio de Wright. Em decorrência da falta de graus de liberdade, o ajuste ao modelo de equilíbrio

Tabela 1. Freqüências alélicas para os locos $P g i 2, P g d 2, P g m 1$ e Estl em 31 acessos e cinco cultivares de girassol.

\begin{tabular}{|c|c|c|c|c|c|c|c|c|c|c|c|c|}
\hline \multirow[t]{2}{*}{ Material } & \multicolumn{2}{|c|}{ Pgi2 } & \multicolumn{2}{|c|}{$\mathrm{Pgd2}$} & \multicolumn{2}{|c|}{$P g m 1$} & \multicolumn{6}{|c|}{ Est1 } \\
\hline & $a$ & $b$ & $a$ & $b$ & $a$ & $b$ & $a$ & $b$ & $c$ & $d$ & $e$ & $f$ \\
\hline AMES 3322 & 1,00 & 0,00 & 0,47 & 0,53 & 1,00 & 0,00 & 0,00 & 0,00 & 0,00 & 0,38 & 0,00 & 0,62 \\
\hline AMES 3326 & 1,00 & 0,00 & 0,62 & 0,38 & 0,00 & 1,00 & 0,00 & 0,10 & 0,07 & 0,00 & 0,00 & 0,83 \\
\hline PI 201812 & 1,00 & 0,00 & 0,05 & 0,95 & 0,90 & 0,10 & 0,00 & 0,03 & 0,00 & 0,00 & 0,00 & 0,97 \\
\hline PI 219649 & 0,82 & 0,18 & 0,00 & 1,00 & 0,75 & 0,25 & 0,40 & 0,03 & 0,00 & 0,28 & 0,00 & 0,28 \\
\hline PI 240660 & 1,00 & 0,00 & 0,10 & 0,90 & 0,00 & 1,00 & 0,43 & 0,05 & 0,12 & 0,27 & 0,00 & 0,13 \\
\hline PI 250612 & 1,00 & 0,00 & 0,20 & 0,80 & 0,00 & 1,00 & 0,68 & 0,05 & 0,27 & 0,00 & 0,00 & 0,00 \\
\hline PI 253417 & 0,68 & 0,32 & 0,30 & 0,70 & 0,23 & 0,77 & 0,53 & 0,18 & 0,00 & 0,00 & 0,00 & 0,28 \\
\hline PI 267665 & 0,60 & 0,40 & 0,07 & 0,93 & 0,00 & 1,00 & 0,25 & 0,07 & 0,00 & 0,30 & 0,00 & 0,38 \\
\hline PI 289626 & 0,82 & 0,18 & 0,50 & 0,50 & 0,08 & 0,92 & 0,42 & 0,08 & 0,30 & 0,20 & 0,00 & 0,00 \\
\hline PI 296286 & 0,88 & 0,12 & 0,37 & 0,63 & 0,10 & 0,90 & 0,50 & 0,12 & 0,05 & 0,05 & 0,00 & 0,28 \\
\hline PI 340781 & 0,97 & 0,03 & 0,05 & 0,95 & 0,15 & 0,85 & 0,00 & 0,15 & 0,00 & 0,53 & 0,00 & 0,32 \\
\hline PI 340782 & 0,95 & 0,05 & 0,10 & 0,90 & 0,03 & 0,97 & 0,10 & 0,22 & 0,00 & 0,30 & 0,00 & 0,38 \\
\hline PI 343785 & 0,78 & 0,22 & 0,98 & 0,02 & 0,00 & 1,00 & 0,37 & 0,00 & 0,00 & 0,00 & 0,00 & 0,63 \\
\hline PI 343786 & 0,83 & 0,17 & 0,52 & 0,48 & 0,00 & 1,00 & 0,35 & 0,00 & 0,07 & 0,42 & 0,00 & 0,17 \\
\hline PI 372176 & 0,97 & 0,03 & 0,00 & 1,00 & 0,02 & 0,98 & 0,60 & 0,08 & 0,00 & 0,18 & 0,00 & 0,13 \\
\hline PI 380567 & 1,00 & 0,00 & 0,07 & 0,93 & 0,02 & 0,98 & 0,48 & 0,00 & 0,42 & 0,00 & 0,00 & 0,10 \\
\hline PI 380574 & 0,55 & 0,45 & 0,22 & 0,78 & 0,05 & 0,95 & 0,00 & 0,08 & 0,00 & 0,70 & 0,00 & 0,22 \\
\hline PI 380575 & 0,97 & 0,03 & 0,03 & 0,97 & 0,03 & 0,97 & 0,00 & 0,48 & 0,00 & 0,32 & 0,00 & 0,20 \\
\hline PI 380576 & 0,83 & 0,17 & 0,13 & 0,87 & 0,57 & 0,43 & 0,37 & 0,07 & 0,00 & 0,22 & 0,00 & 0,35 \\
\hline PI 386235 & 1,00 & 0,00 & 0,05 & 0,95 & 0,02 & 0,98 & 0,00 & 0,00 & 0,82 & 0,18 & 0,00 & 0,00 \\
\hline PI 432514 & 1,00 & 0,00 & 0,37 & 0,63 & 0,00 & 1,00 & 0,00 & 0,00 & 0,40 & 0,32 & 0,28 & 0,00 \\
\hline PI 432518 & 1,00 & 0,00 & 0,15 & 0,85 & 0,05 & 0,95 & 0,05 & 0,20 & 0,00 & 0,25 & 0,00 & 0,50 \\
\hline PI 487194 & 0,95 & 0,05 & 0,25 & 0,75 & 0,00 & 1,00 & 0,03 & 0,10 & 0,08 & 0,52 & 0,00 & 0,27 \\
\hline PI 497244 & 0,78 & 0,22 & 0,37 & 0,63 & 0,12 & 0,88 & 0,17 & 0,17 & 0,00 & 0,27 & 0,00 & 0,40 \\
\hline PI 497930 & 1,00 & 0,00 & 0,00 & 1,00 & 0,00 & 1,00 & 0,60 & 0,40 & 0,00 & 0,00 & 0,00 & 0,00 \\
\hline PI 497937 & 0,77 & 0,23 & 0,27 & 0,73 & 0,33 & 0,67 & 0,03 & 0,48 & 0,00 & 0,00 & 0,00 & 0,48 \\
\hline PI 500686 & 0,73 & 0,27 & 0,43 & 0,57 & 0,00 & 1,00 & 0,00 & 0,00 & 0,00 & 0,00 & 0,00 & 1,00 \\
\hline PI 500687 & 0,77 & 0,23 & 0,20 & 0,80 & 0,02 & 0,98 & 0,18 & 0,02 & 0,42 & 0,38 & 0,00 & 0,00 \\
\hline PI 507925 & 0,88 & 0,12 & 0,13 & 0,87 & 0,08 & 0,92 & 0,17 & 0,22 & 0,00 & 0,07 & 0,00 & 0,55 \\
\hline PI 526265 & 1,00 & 0,00 & 0,48 & 0,52 & 0,03 & 0,97 & 0,27 & 0,03 & 0,02 & 0,25 & 0,00 & 0,43 \\
\hline PI 549003 & 0,87 & 0,13 & 0,20 & 0,80 & 0,25 & 0,75 & 0,08 & 0,02 & 0,03 & 0,22 & 0,00 & 0,65 \\
\hline Média & 0,88 & 0,12 & 0,25 & 0,75 & 0,16 & 0,84 & 0,23 & 0,11 & 0,10 & 0,21 & 0,01 & 0,34 \\
\hline Cargill 11 & 1,00 & 0,00 & 0,50 & 0,50 & 0,50 & 0,50 & 0,00 & 0,00 & 0,00 & 1,00 & 0,00 & 0,00 \\
\hline M742 & 1,00 & 0,00 & 0,43 & 0,57 & 1,00 & 0,00 & 0,50 & 0,00 & 0,00 & 0,00 & 0,00 & 0,50 \\
\hline M734 & 1,00 & 0,00 & 0,50 & 0,50 & 1,00 & 0,00 & 0,00 & 0,00 & 0,00 & 0,50 & 0,00 & 0,50 \\
\hline EMBRAPA 122 & 1,00 & 0,00 & 0,27 & 0,73 & 0,22 & 0,78 & 0,07 & 0,10 & 0,00 & 0,37 & 0,00 & 0,47 \\
\hline DK180 & 1,00 & 0,00 & 0,42 & 0,58 & 0,55 & 0,45 & 0,25 & 0,52 & 0,00 & 0,10 & 0,00 & 0,13 \\
\hline Média & 1,00 & 0,00 & 0,42 & 0,58 & 0,65 & 0,35 & 0,16 & 0,12 & 0,00 & 0,39 & 0,00 & 0,32 \\
\hline
\end{tabular}


de Wright não pôde ser testado na PI 497930. Nenhum destes dois modelos de equilíbrio se ajustou às PIs 250612 e 253417; já a PI 380576 apresentou um $\bar{f}$ negativo. Isto indica um excesso de heterozigotos nestes materiais. Este último fato pode ser conseqüência do comportamento reprodutivo desta planta aliado ao método de multiplicação dos acessos, que procurou privilegiar o cruzamento entre todos os indivíduos de um mesmo acesso.
Os dados de distância genética (Tabela 3) foram baixos na maioria dos acessos e cultivares de girassol, variando entre 0,003 e 0,418 . Isto indica uma grande semelhança entre estes materiais nos sistemas enzimáticos analisados. O polimorfismo detectado por estes marcadores isoenzimáticos não foi suficiente para gerar um dendrograma com um nível estatisticamente significativo de consistência nos nós. Entretanto, eles podem vir a ser úteis na discrimina-

Tabela 2. Estimativas de heterozigosidade esperada $\left(H_{e}\right)$, observada $\left(H_{o}\right)$, índice médio de fixação $(\bar{f})$, número médio de alelos por loco polimórfico $(A)$; proporção de alelos em cada acesso ou cultivar $\left(P_{A}\right)$ e porcentagem de locos polimórficos $(P$ - com intervalo de confiança de 0,99$)$ para os locos isoenzimáticos de acessos e cultivares de girassol.

\begin{tabular}{|c|c|c|c|c|c|c|c|c|c|c|c|c|c|c|}
\hline \multirow[t]{2}{*}{ Material } & \multicolumn{2}{|c|}{$\mathrm{Pgi2}$} & \multicolumn{2}{|c|}{$\mathrm{Pgd} 2$} & \multicolumn{2}{|c|}{ Pgml } & \multicolumn{2}{|c|}{ Est 1} & \multicolumn{3}{|c|}{ Média } & \multirow[t]{2}{*}{$A$} & \multirow[t]{2}{*}{$P_{A}$} & \multirow[t]{2}{*}{$P$} \\
\hline & $\mathrm{He}$ & Ho & $\mathrm{He}$ & Ho & $\mathrm{He}$ & Ho & $\mathrm{He}$ & Ho & $\overline{H e}$ & $\overline{H o}$ & $f^{(1)}$ & & & \\
\hline AMES 3322 & - & - & 0,51 & 0,47 & - & - & 0,48 & 0,37 & 0,16 & 0,14 & - & 1,50 & 0,50 & 33,3 \\
\hline AMES 3326 & - & - & 0,48 & 0,37 & - & - & 0,30 & 0,17 & 0,13 & 0,09 & $0,31^{\mathrm{ns}}$ & 1,75 & 0,58 & 33,3 \\
\hline PI 201812 & - & - & 0,10 & 0,03 & 0,18 & 0,07 & 0,07 & 0,07 & 0,06 & 0,03 & $0,52^{\mathrm{ns}}$ & 1,75 & 0,58 & 33,3 \\
\hline PI 219649 & 0,30 & 0,37 & - & - & 0,38 & 0,23 & 0,69 & 0,60 & 0,23 & 0,20 & $0,13^{\text {ns }}$ & 2,25 & 0,75 & 50,0 \\
\hline PI 240660 & - & - & 0,18 & 0,20 & - & - & 0,72 & 0,60 & 0,15 & 0,13 & - & 2,25 & 0,75 & 33,3 \\
\hline PI 250612 & - & - & 0,33 & 0,27 & - & - & 0,47 & 0,17 & 0,13 & 0,07 & $0,45^{*}$ & 1,75 & 0,58 & 33,3 \\
\hline PI 253417 & 0,44 & 0,43 & 0,43 & 0,20 & 0,36 & 0,40 & 0,61 & 0,63 & 0,31 & 0,28 & $0,10^{*}$ & 2,25 & 0,75 & 66,7 \\
\hline PI 267665 & 0,49 & 0,47 & 0,13 & 0,07 & - & - & 0,71 & 0,70 & 0,22 & 0,21 & - & 2,25 & 0,75 & 50,0 \\
\hline PI 289626 & 0,30 & 0,37 & 0,51 & 0,60 & 0,16 & 0,17 & 0,70 & 0,63 & 0,28 & 0,29 & - & 2,50 & 0,83 & 66,7 \\
\hline PI 296286 & 0,21 & 0,17 & 0,47 & 0,40 & 0,18 & 0,13 & 0,66 & 0,77 & 0,25 & 0,24 & - & 2,75 & 0,92 & 66,7 \\
\hline PI 340781 & 0,07 & 0,07 & 0,10 & 0,10 & 0,26 & 0,30 & 0,60 & 0,57 & 0,17 & 0,17 & - & 2,25 & 0,75 & 50,0 \\
\hline PI 340782 & 0,10 & 0,10 & 0,18 & 0,20 & 0,07 & 0,07 & 0,72 & 0,70 & 0,18 & 0,18 & - & 2,50 & 0,83 & 50,0 \\
\hline PI 343785 & 0,35 & 0,43 & 0,03 & 0,03 & - & - & 0,47 & 0,33 & 0,14 & 0,13 & - & 1,75 & 0,58 & 33,3 \\
\hline PI 343786 & 0,28 & 0,33 & 0,51 & 0,50 & - & - & 0,68 & 0,47 & 0,25 & 0,22 & $0,12^{\mathrm{ns}}$ & 2,25 & 0,75 & 50,0 \\
\hline PI 372176 & 0,07 & 0,07 & - & - & 0,03 & 0,03 & 0,59 & 0,47 & 0,12 & 0,09 & - & 2,25 & 0,75 & 16,7 \\
\hline PI 380567 & - & - & 0,13 & 0,13 & 0,03 & 0,03 & 0,59 & 0,67 & 0,13 & 0,14 & - & 2,00 & 0,67 & 33,3 \\
\hline PI 380574 & 0,50 & 0,63 & 0,35 & 0,30 & 0,10 & 0,10 & 0,46 & 0,43 & 0,23 & 0,24 & - & 2,25 & 0,75 & 66,7 \\
\hline PI 380575 & 0,07 & 0,07 & 0,07 & 0,07 & 0,07 & 0,07 & 0,64 & 0,60 & 0,14 & 0,13 & - & 2,25 & 0,75 & 16,7 \\
\hline PI 380576 & 0,28 & 0,20 & 0,24 & 0,20 & 0,50 & 0,67 & 0,70 & 0,77 & 0,29 & 0,31 & $0,07^{(2)}$ & 2,50 & 0,83 & 66,7 \\
\hline PI 386235 & - & - & 0,10 & 0,03 & 0,03 & 0,03 & 0,30 & 0,03 & 0,07 & 0,02 & $0,77^{\mathrm{ns}}$ & 1,75 & 0,58 & 33,3 \\
\hline PI 432514 & - & - & 0,47 & 0,60 & - & - & 0,67 & 0,73 & 0,19 & 0,22 & - & 1,75 & 0,58 & 33,3 \\
\hline PI 432518 & - & - & 0,26 & 0,30 & 0,10 & 0,10 & 0,66 & 0,73 & 0,17 & 0,19 & - & 2,25 & 0,75 & 50,0 \\
\hline PI 487194 & 0,10 & 0,10 & 0,38 & 0,23 & - & - & 0,65 & 0,53 & 0,19 & 0,14 & $0,24^{\mathrm{ns}}$ & 2,50 & 0,83 & 50,0 \\
\hline PI 497244 & 0,35 & 0,23 & 0,47 & 0,47 & 0,21 & 0,23 & 0,73 & 0,50 & 0,29 & 0,24 & $0,18^{\mathrm{ns}}$ & 2,50 & 0,83 & 66,7 \\
\hline PI 497930 & - & - & - & - & - & - & 0,49 & 0,13 & 0,08 & 0,02 & $0,73^{(3)}$ & 1,25 & 0,42 & 16,7 \\
\hline PI 497937 & 0,36 & 0,07 & 0,40 & 0,27 & 0,45 & 0,33 & 0,54 & 0,30 & 0,29 & 0,16 & $0,45^{\mathrm{ns}}$ & 2,25 & 0,75 & 66,7 \\
\hline PI 500686 & 0,40 & 0,40 & 0,50 & 0,27 & - & - & - & - & 0,15 & 0,11 & $0,26^{\mathrm{ns}}$ & 1,50 & 0,50 & 33,3 \\
\hline PI 500687 & 0,36 & 0,40 & 0,33 & 0,33 & 0,03 & 0,03 & 0,66 & 0,70 & 0,23 & 0,24 & - & 2,50 & 0,83 & 50,0 \\
\hline PI 507925 & 0,21 & 0,23 & 0,24 & 0,27 & 0,16 & 0,17 & 0,63 & 0,57 & 0,20 & 0,21 & - & 2,50 & 0,83 & 66,7 \\
\hline PI 526265 & - & - & 0,51 & 0,37 & 0,07 & 0,07 & 0,69 & 0,70 & 0,21 & 0,19 & - & 2,50 & 0,83 & 33,3 \\
\hline PI 549003 & 0,24 & 0,13 & 0,33 & 0,07 & 0,38 & 0,30 & 0,53 & 0,30 & 0,25 & 0,13 & $0,46^{\mathrm{ns}}$ & 2,75 & 0,93 & 66,7 \\
\hline Cargill 11 & - & - & 0,51 & 1,00 & 0,51 & 1,00 & - & - & 0,17 & 0,33 & - & 1,50 & 0,50 & 33,3 \\
\hline M742 & - & - & 0,50 & 0,87 & - & - & 0,51 & 1,00 & 0,17 & 0,31 & - & 1,50 & 0,50 & 33,3 \\
\hline M734 & - & - & 0,51 & 1,00 & - & - & 0,51 & 1,00 & 0,17 & 0,33 & - & 1,50 & 0,50 & 33,3 \\
\hline EMBRAPA 122 & - & - & 0,40 & 0,40 & 0,35 & 0,37 & 0,64 & 0,83 & 0,23 & 0,24 & - & 2,25 & 0,75 & 50,0 \\
\hline DK180 & - & - & 0,49 & 0,83 & 0,50 & 0,17 & 0,65 & 0,97 & 0,28 & 0,33 & - & 2,25 & 0,75 & 50,0 \\
\hline Média de acessos ${ }^{(4)}$ & 0,21 & 0,17 & 0,37 & 0,24 & 0,26 & 0,11 & 0,76 & 0,48 & 0,27 & 0,17 & - & 2,16 & 0,72 & 66,7 \\
\hline Média de cultivares $^{(4)}$ & - & - & 0,49 & 0,82 & 0,45 & 0,31 & 0,70 & 0,76 & 0,27 & 0,31 & - & 1,80 & 0,60 & 50,0 \\
\hline
\end{tabular}

(1)Índice de fixação obtido para os acessos cuja probabilidade de adequação ao modelo de equilíbrio de Hardy-Weinberg foi $\mathrm{P}<5 \%$. (2)Devido ao índice ter sido negativo, não foi ajustado ao modelo de equilíbrio de Wright. ${ }^{(3)}$ Não houve graus de liberdade para o teste de ajuste ao modelo. ${ }^{(4)}$ Média estimada a partir da análise conjunta de todos acessos, cultivares ou locos. ${ }^{n} \chi^{2}$ não-significativo a $5 \%$ de probabilidade. $* \chi^{2}$ significativo a $5 \%$ de probabilidade. 
Tabela 3. Dados de distância genética entre os acessos e cultivares de girassol.

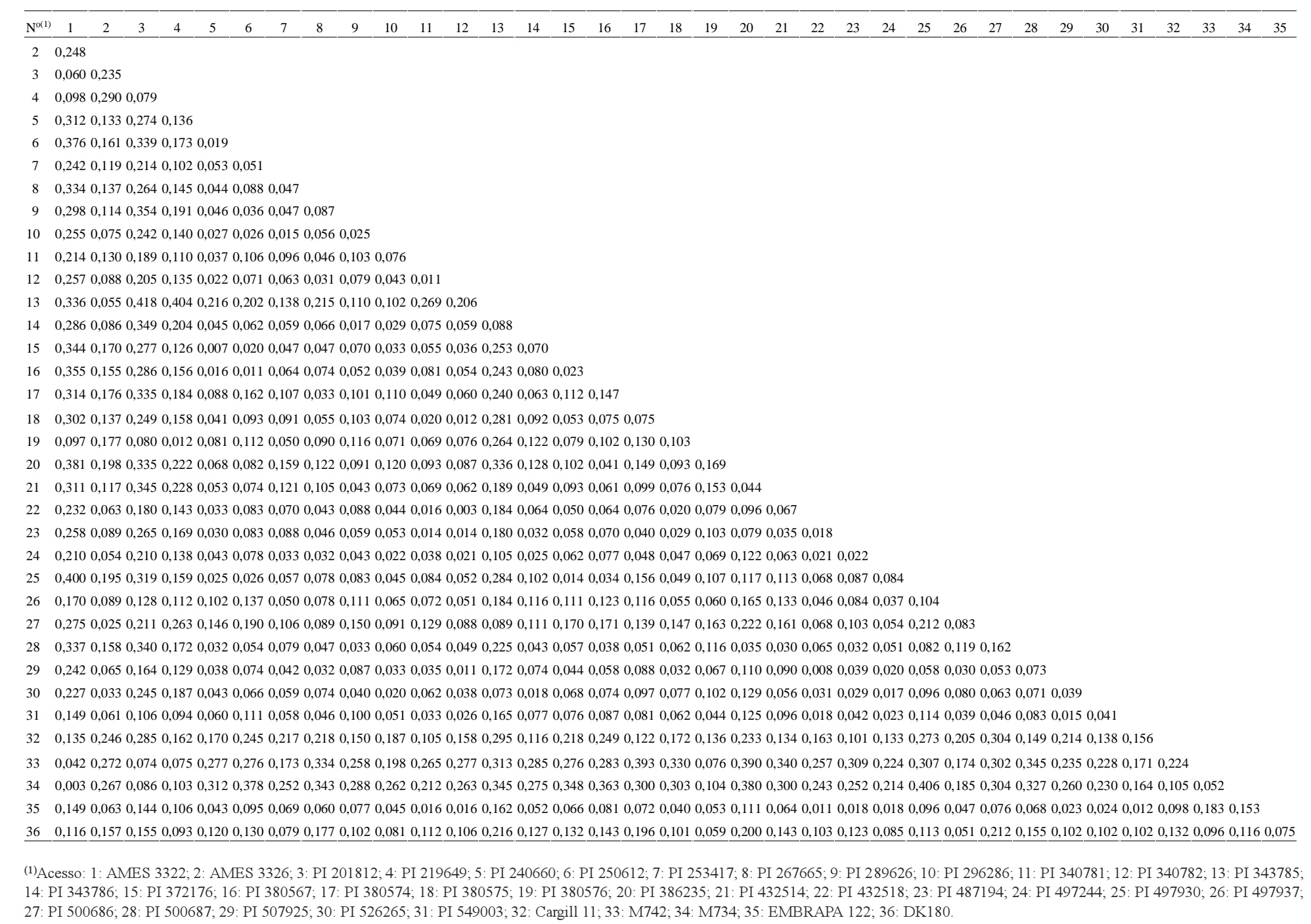


ção destes materiais, se forem associados a outros marcadores.

\section{Conclusões}

1. Dos seis sistemas enzimáticos analisados, quatro são polimórficos, e os indivíduos são facilmente discriminados entre si em todas as condições experimentais utilizadas.

2. Do total de alelos detectados, $75 \%$ são compartilhados entre acessos e cultivares de girassol, indicando, assim, uma homogeneidade considerável nos sistemas isoenzimáticos estudados.

3. A maior quantidade de alelos encontrada em Est1, e a facilidade de análise deste sistema, o tornam um ótimo candidato a marcador, no que diz respeito ao girassol.

4. Os testes de adequação aos modelos de equilíbrio de Hardy-Weinberg e de Wright evidenciam diferentes comportamentos reprodutivos entre os acessos; alguns são mais panmíticos e outros, mais endogâmicos.

5. Os dados de distância genética, na maioria dos acessos e cultivares de girassol, mostram um grau pequeno de diversidade genética nestes marcadores isoenzimáticos.

\section{Agradecimentos}

À CAPES, FAEPA e Universidade Estadual de Londrina, pelo apoio financeiro recebido e à Embrapa-Centro Nacional de Pesquisa de Soja, pelos aquênios de girassol utilizados neste estudo.

\section{Referências}

ALFENAS, A. C.; PETERS, I.; BRUNE, W.; PASSADOR, G. C. Eletroforese de proteínas e isoenzimas de fungos e essências florestais. Viçosa : UFV, 1991. 242 p

BI, I. Z.; MAQUET, A.; DEGREEF, J.; WATHELET, B.; BAUDOIN, J. P. Sample size for collecting seeds in germplasm conservation: the case of the Lima bean (Phaseolus lunatus L.). Theoretical and Applied Genetics, Berlin, v. 97, p. 187-194, 1998

BUZZETTI, A. R. Cresce a produção de girassol. Óleos e Grãos, São Bernardo do Campo, v. 8, n. 46, p. 34-38, 1999
CARRÃO-PANIZZI, M. C.; MANDARINO, J. M. G. Girassol: derivados protéicos. Londrina : Embrapa-CNPSo, 1994. 27 p. (Embrapa-CNPSo. Documentos, 74).

CARRERA, A.; POVERENE, M. Isozyme variation in Helianthus petiolaris and sunflower, H. annuus. Euphytica, Dordrecht, v. 81, n. 3, p. 251-257, 1995.

CARRERA, A.; POVERENE, M. Variabilidad genética en girasol mediante marcadores isoenzimáticos. Investigación Agraria. Producción y Protección Vegetales, Madrid, v. 6, n. 3, p. 281-293, 1991.

CASTIGLIONI, V. B. R.; BALLA, A. Aspectos da cultura de girassol no Brasil. Londrina : Embrapa-CNPSo, 1996. $11 \mathrm{p}$

COUSINEAU, J. C.; DONNELLY, D. J. Use of isoenzyme analysis to characterize raspberry cultivars and detect cultivar mislabeling. HortScience, Alexandria, v. 27, p. $1023-$ $1025,1992$.

CRONN, R.; BROTHERS, M.; KLIER, K.; BRETTING, P. K.; WENDEL, J. F. Allozyme variation in domesticated annual sunflower and its wild relatives. Theoretical and Applied Genetics, Berlin, v. 95, p. 532-545, 1997.

DRY, P. J. Isozyme variation between Helianthus annuus rust differential sunflower lines. In: CONFERENCIA INTERNACIONAL DE GIRASOL, 11., 1985, Mar del Plata. Actas... Buenos Aires : Asociación Argentina de Girasol, 1985. p. 611-617.

EMBRAPA. Centro Nacional de Pesquisa de Soja (Londrina, PR). Subsídios para a elaboração do programa nacional de pesquisa de girassol. Londrina : EmbrapaCNPSo, $1980.17 \mathrm{p}$

EPPERSON, J. E.; PACHINO, D. H.; GUEVARA, C. L. A cost analysis of mainting cassava plant genetic resources Crop Science, Madison, v. 37, p. 1641-1649, 1997.

ESTADOS UNIDOS. Department of Agriculture. Foreign Agriculture Service. USDAestimates. Disponível: site FAS Online. URL: http://www.fas.usda.gov/oilseeds/circular/ 2000/00-06/toc.htm. Consultado em jul. 2000

HARTL, D. L. A primer of population genetics. Sunderland : Sinauer, 1981. 191 p.

HINTUM, T. J. L.; BOTHMER, R.; VISSER, D. L. Sampling strategies for composing a core collection of cultivated barley (Hordeum vulgare s. lat.) collected in China. Hereditas, Lund, v. 122, p. 7-17, 1995.

HUANG, H.; LAYNE, D. R. Using isozyme polymorphisms for identifying and assessing genetic 
variation in cultivated pawpaw [Asimina triloba $(\mathrm{L}$.) Dunal]. American Society for Horticultural Science Journal, Alexandria, v. 122, n. 4, p. 504-511, 1997.

KAHLER, A. L.; LAY, C. L. Genetics of electrophoretic variants in the annual sunflower. Journal of Heredity, Cary, v. 76, n. 5, p. 335-340, 1985

KENNEDY, L. S.; THOMPSON, P. G. Identification of sweet potato cultivars using isozyme analysis. HortScience, Alexandria, v. 26, p. 300-302, 1991.

MANDARINO, J. M. G. Características bioquímicas e nutricionais do óleo e do farelo de girassol. Londrina : Embrapa-CNPSo, 1992. 25 p. (Embrapa-CNPSo. Documentos, 52)

MAQUET, A.; BI, I. Z.; DELVAUX, M.; WATHELET, B.; BAUDOIN, J. P. Genetics structure of a Lima bean base collection using allozyme markers. Theoretical and Applied Genetics, Berlin, v. 95, p. 980-991, 1997.

MATIELLO, R. R.; BARBOSA NETO, J. F.; SERENO, M. J. C. M.; TADERKA, I.; PEGORARO, D. G. Variabilidade genética através de polimorfismos isoenzimáticos em aveias hexaplóides. Pesquisa Agropecuária Brasileira, Brasília, v. 33, n. 6, p. 913-918, jun. 1998

MESSINA, R.; TESTOLIN, R.; MORGANTE, M Isozymes for cultivar identification in kiwifruit HortScience, Alexandria, v. 26, p. 899-902, 1991.

MILLER, M. P. TFPGA: tools for population genetic analyses. Disponível: site Arizona State University (set 2000). URL: http://www.public.asu.edu/ mmille8/. Consultado em 13 nov. 2000

NEI, M. Genetic distance between populations. American Naturalist, Chicago, v. 106, n. 949, p. 283-292, 1972.

POLIGNANO, G. B.; QUINTANO, G.; BISIGNANO, V.; UGGENTI, P.; DELLA GATTA, C.; ALBA, E. Enzyme polymorphism in faba bean (Vicia faba L. minor) accessions. Genetic interpretation and value for classification. Euphytica, Dordrecht, v. 102, p. 169-176, 1998

QUILLET, M. C.; VEAR, F.; BRANLARD, G. The use of isozyme polymorphism for identification of sunflower (Helianthus annuus) inbred lines. Journal of Genetics \& Breeding, Rome, v. 46, n. 4, p. 295-304, 1992.

REYES, F. G. R.; GARIBAY, C. B.; UNGARO, M. R. G.; TOLEDO, M. C. F. Girassol: cultura e aspectos químicos, nutricionais e tecnológicos. Campinas : Fundação Cargill, 1985. $88 \mathrm{p}$.

RIESEBERG, L. H.; SEILER, G. J. Molecular evidence and the origin and development of the domesticated sunflower (Helianthus annuus, Asteraceae). Economic Botany, New York, v. 44, n. 3, p. 79-91, 1990.

SHAMINA, A.; ZACHARIAH, T. J.; SASIKUMAR, B.; GEORGE, J. K. Biochemical variation in tumeric (Curcuma longa Linn.) accessions based on isozyme polymorphism. Journal of Horticultural Science and Biotechnology, Ashford, v. 73, n. 4, p. 479-483, 1998.

TAO, R.; SUGIURA,A. Cultivar identification of Japanese persimmon by leaf isozymes. HortScience, Alexandria, v. 22 , p. $932-935,1987$

URSLA-FERNANDO, W. M.; HAYWARD, M. D.; KEARSEY, M. J. Isozyme and quantitative traits polymorphisms in European provenances of perennial ryegrass (Lolium perenne L.). Euphytica, Dordrecht, v. 93 , p. 263-269, 1997.

VOEST, D.; HARTMANN, H.; SCHNABL, H. Identification of Helianthus genotypes by new isoenzymes systems. Journal of Applied Botany, Berlin, v. 67, p. 124127,1993 